\title{
Study of quality of life and characteristic factors in women with breast cancer undergoing different types of therapy
}

\author{
Redhwan A. Al-Naggar ${ }^{1}$, Muhamed T Osman ${ }^{2}$, Nameer Al-Baghdadi ${ }^{3 *}$ \\ ${ }^{1}$ Faculty of Medicine, Universiti Teknologi MARA (UiTM), Selangor, Malaysia. \\ ${ }^{2}$ Faculty of Medicine and Defence Health; National Defence University of Malaysia (UPNM), Kuala Lumpur, Malaysia. \\ ${ }^{3}$ Al-Yarmook Teaching Hospital, Al-Mustansiriya University, Baghdad, Iraq.
}

\begin{tabular}{l}
\hline ARTICLE INFO \\
\hline Article history: \\
Received on: $21 / 06 / 2016$ \\
Revised on: $13 / 07 / 2016$ \\
Accepted on: $09 / 08 / 2016$ \\
Available online: $26 / 09 / 2016$ \\
\hline Key words: \\
Quality of Life (QoL), breast \\
cancer, chemotherapy, \\
radiotherapy.
\end{tabular}

\begin{abstract}
Breast cancer is the most common cancer among women and an increasingly important issue is to evaluate quality of life (QoL) among these patients. The objective of this study was to appreciate the QoL and associated factors among breast cancer womenundergoing different types of therapy. A cross-sectional study was carried out among 166 breast cancer women from two specialized centres in Baghdad, Iraq, from February 2014 to December 2014. The questionnaire used in this study was "The Functional Assessment of Cancer TherapyBreast (FACT-B)". The majority were employee $(60.3 \%)$, with high school education $(63.2 \%)$, with no family history of cancer $(79.5 \%)$. Majority were diagnosed with grade II $(56.6 \%)$ and tumor size less than $2 \mathrm{~cm}$ in diameter $(95.8 \%)$. The majority of women underwent mastectomy $(98.2 \%)$, received chemotherapy, radiotherapy, and Tamoxifen therapy $(89.8 \%, 29.5 \%$, and $36.1 \%$; respectively). The study found a significant difference between the quality of life among cancer patients and job, stage of cancer, size of tumor, and radiotherapy. Job, stage of cancer, size of tumor, and radiotherapy significantly influenced the women QoL. Therefore, more attention on these variables is highly recommended when dealing with breast cancer patients undergoing different types of therapy.
\end{abstract}

\section{INTRODUCTION}

According to World Cancer Report 2014, cancers among the leading causes of morbidity and mortality worldwide (World Cancer Report, 2014). Approximately 14 million new cases and 8.2 million cancer related deaths in 2012 (World Cancer Report, 2014).Middle and low-income nations recorded $70 \%$ of all cancer death. If there are no prevention measures urgently implemented worldwide, the death from cancer will be rise to more than 13.1 million in 2030 (Global Health Observatory, 2012). For breast cancer 1.7 million new cases of breast cancer were diagnosed worldwide in 2012, accounting for $25 \%$ of all new cancer cases in women (International Agency for Research on Cancer, Globocan, 2012). Breast cancer is one of the most common types of cancers among women in the Arabic

\section{* Corresponding Author}

Nameer Al-Baghdadi, Al-Yarmook Teaching Hospital, Al-Mustansiriya

University, Baghdad, Iraq.Email: nameeralbaghdadi @gmail.com world (Salim et al., 2009; Najla et al., 2010). The Arabic world has an overall population of around 380 million and extends over a large geographical area in northern Africa and Middle East. The incidence of breast cancer in the Arabic world is less than the western countries (Najla et al., 2010; Ozmen et al., 2009). Breast cancer rates are increasing among developing countries of Arabic world including Egypt, Lebanon, Syria, Jordan, Saudi Arabia, and Iraq (Ibrahim et al., 2013; Ozmen et al., 2009). In Iraq, breast cancer is the leading cancer among Iraqi women (Iraqi National Cancer Research Center, 2013). About 23,792 breast cancer cases were registered among females in Iraq aged 15 years old and above.

This number represented $33.8 \%$ of the total cancer cases among females from 2000-2009 registered in Iraq (Al-Hashimi and Wang, 2014). According to Globocan (2008), the Age Standardized Incidence Rates (ASR) in Iraq was $(31.1 / 100,000)$, similar as compared to neighbour Arabs countries such as Kuwait (47.7), Saudi Arabia (22.4), Jordan (47.0), and Syria (23.0). 
Advances in breast cancer prevention, screening, diagnostic and treatment additionally brought about expanded survival (National Cancer Institute, 2012). Therefore, coping with this disease is common experience. Furthermore, as other Arab ladies, Iraqi ladies have social taboos with regard to breast cancer (Abu-Naser, 2007). Breast cancer diagnosis would become a fear to mothers who would think that their daughters would not get married when people know that they have breast cancer (AbuNaser, 2007).

Breast cancer survivors comprise the largest number of all survivors which is approximately about 2.5 million (Centers for Disease Control and Prevention \& Lance Armstrong Foundation, 2004). However, 33\% of survivors experience ongoing many problems such as physical, psychological and financial cost regarding their treatment and diagnosis (McCabe et al., 2013). Appropriate subsequent consideration is regularly not conveyed and the psychosocial needs of malignancy patients are frequently not tended to. Additionally, numerous patients finish their essential treatment uninformed of their future risk and wellbeing chances and not well prepared to manage their future health care needs (McCabe et al., 2013). Thus, the oncology group and numerous national associations have started to concentrate on survivorship as a focal part of oncology consideration (McCabe et al., 2013, Rauscher et al.,2011). Cancer survivorship is a moderately new, including Iraqis breast cancer survivors who may have extra needs contrasted with survivors from other western nations.

In the Arab world, especially among breast cancer women only few studies about QoL were conducted. However, no such study was conducted so far in Iraq. Hence, this study aimed at exploring the QoL among women with breast cancer underlying different types of therapy, so as to help improve health care in such area and topic.

\section{MATERIALS AND METHODS}

The present study is a cross-sectional one where data collected out of 166 breast cancer patients from two specialized centres in Baghdad, Iraq from February 2014 to December 2014. Only native Arabic language females who are older than eighteen years were chosen for the study. Also, they had at least one year history of cancer diagnosis. Other women were excluded, especially those who had other malignancies, had metastasis, or other acute physical, cognitive or psychiatric health problems. The methodological tool was a questionnaire that was handed over to patients during their clinical visit. The study was conducted in accordance with the Helsinki Declaration and informed consent was obtained from the study participants. The study was approved by the ethics committees of the two specialized centres.

\section{Instrument}

More specifically, the questionnaire provided to patients was "Functional Assessment of Cancer Therapy-Breast (FACTB)" questionnaire, version 4. Authors have got permission officially to use this questionnaire from its source. It is included measures of physical, social/family, emotional, and functional wellbeing. In the emotional element, two items were provided, namely "worried about risk of breast cancer in the family members" and "worried about effects of stress on the illness". Body image-related element included three items, namely "feeling sexually attractive", "feeling self-conscious about the way one dressed", and "feeling like a woman". Reliability, validity and responsiveness to clinical change of FACT instruments were demonstrated extensively.

\section{Statistical analysis}

To evaluate the final model for univariate and multiple linear regression, ANOVA, t-test and backward analysis were carried out.

\section{RESULTS}

In this study, there were 166 patient participants, aged between 30 and 67 (Mean $=49.6 \pm 8.2$ ). Majority of them were 40 years of age or older $(71.7 \%)$, employees $(60.3 \%)$, with high school education $(63.2 \%)$, with no family history of cancer $(79.5 \%)$ and were diagnosed with Grade II of tumor $(56.6 \%)$ with tumor size of less than $2 \mathrm{~cm}$ in diameter $(95.8 \%)$. Regarding the treatment, the majority of participants underwent mastectomy $(98.2 \%)$, received chemotherapy, radiotherapy, and Tamoxifen therapy $(89.8 \%, 29.5 \%$, and $36.1 \%$; respectively) (Table 1).

Table 1: Socio-demographic characteristics of breast cancer patients $(\mathrm{n}=166)$.

\begin{tabular}{lccc}
\hline & Category & Frequency & $\mathbf{\%}$ \\
\hline \multirow{2}{*}{ Age (Year) } & $<40$ & 48 & 28.9 \\
& $\geq 40$ & 118 & 71.7 \\
\hline \multirow{2}{*}{ Employment status } & Employee & 100 & 60.3 \\
& Non-employee & 66 & 39.7 \\
\hline \multirow{3}{*}{ Educational status } & Literacy & 13 & 7.8 \\
& School & 105 & 63.2 \\
& University & 48 & 29 \\
\hline \multirow{2}{*}{ Family History of cancer } & Yes & 34 & 20.5 \\
& No & 132 & 79.5 \\
\hline \multirow{2}{*}{ Size of tumour $(\mathrm{cm})$} & $<2$ & 159 & 95.8 \\
& $\geq 2$ & 4 & 2.4 \\
\hline \multirow{2}{*}{ Type of surgery } & Yes & 163 & 98.2 \\
\multirow{2}{*}{ Radiotherapy } & No & 3 & 1.8 \\
\hline \multirow{2}{*}{ Chemotherapy } & Yes & 49 & 29.5 \\
& No & 117 & 70.5 \\
\hline \multirow{2}{*}{ Tamoxifen } & Yes & 149 & 89.8 \\
& No & 17 & 10.2 \\
\hline
\end{tabular}

Age group showed no significant difference in QoL with socio-demographic characteristics and employment status. Moreover, there was a significant association between educational status and Functional Well-Being $(\mathrm{p}=0.006)$, additional $(\mathrm{p}=0.011)$, Physical Well-Being $(\mathrm{p}=0.025)$ and Total QoL $(\mathrm{p}=$ $0.035)$.

Concerning clinical features, a significant association existed between family history of cancer and Physical Well-Being $(p=0.012)$ and additional items $(p=0.001)$. For stage of cancer, a 
significant association showed up between stage of cancer and EWB ( $\mathrm{p}=0.032$ ). However, no significant difference occurred in QoL based on tumour size. Radiotherapy and Physical Well-Being $(\mathrm{p}=0.001)$ showed a significant relation. Association also significantly existed between chemotherapy and EWB $(\mathrm{p}=0.002)$, additional items $(\mathrm{p}=0.001)$. Also, Tamoxifen and PWB $(\mathrm{p}=0.001)$, Overall QOL ( $\mathrm{p}=0.002$ ) showed a significant relation (Table 2).

There was a significant difference between the quality of life among cancer patients and Job, $(\mathrm{F}=1.752, \mathrm{p}=0.019)$. Quality of life among breast cancer patients and educational status, $(\mathrm{F}=$ $1.384, \mathrm{p}=0.114$ ) had no significant relationship. There was no significant difference between life quality and cancer family history $(\mathrm{F}=0.777, \mathrm{p}=0.779)$. Cancer stage showed no significant relationship with life quality among breast cancer patients $(\mathrm{F}=0$. 2.812, $\mathrm{p}=0.000)$. Furthermore, a significant difference existed between the life quality and tumour size $(\mathrm{F}=1.616, \mathrm{p}=0.038)$. There is no significant difference between the quality of life among cancer patients and radiotherapy $(F=1.180, p=0.262)$. There was no significant difference between the quality of life among cancer patients and type of surgery, $(\mathrm{F}=1.292, \mathrm{p}=0.169)$. There was no significant difference between the quality of cancer patient and chemotherapy, $(\mathrm{F}=0.884, \mathrm{p}=0.636)$. However, there was a significant difference between the quality of cancer patients and radiotherapy $(\mathrm{F}=1.180, \mathrm{p}=0.006)$ (Table 3$)$.

Table 2: Socio-demographic and clinical characteristics and Quality of life among cancer patients $(n=166)$.

\begin{tabular}{|c|c|c|c|c|c|c|c|c|c|c|c|c|c|}
\hline \multirow{2}{*}{\multicolumn{2}{|c|}{ Variables }} & \multicolumn{2}{|c|}{ SWB } & \multicolumn{2}{|c|}{ FWB } & \multirow{2}{*}{\multicolumn{2}{|c|}{$\begin{array}{c}\text { EWB } \\
\text { Mean (SD) }\end{array}$}} & \multirow{2}{*}{\multicolumn{2}{|c|}{$\begin{array}{c}\text { PWB } \\
\text { Mean (SD) }\end{array}$}} & \multicolumn{2}{|c|}{ Additional } & \multicolumn{2}{|c|}{ Total scores } \\
\hline & & \multicolumn{2}{|c|}{ Mean (SD) } & \multirow[t]{2}{*}{ Mean } & \multirow[t]{2}{*}{ (SD) } & & & & & \multicolumn{2}{|c|}{ Mean (SD) } & \multicolumn{2}{|c|}{ Mean (SD) } \\
\hline \multicolumn{8}{|c|}{ Age (Year): } & \multirow{4}{*}{\multicolumn{2}{|c|}{ 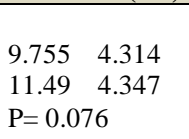 }} & & & & \\
\hline$<40$ & 48 & 18.916 & 2.323 & 15.895 & 2.523 & & & & & 16.458 & 5.974 & 77.854 & 7.216 \\
\hline \multirow[t]{2}{*}{$\geq 40$} & 118 & 17.915 & 2.523 & 15.483 & 2.366 & & & & & 16.305 & 4.946 & 77.898 & 8.507 \\
\hline & & \multicolumn{2}{|c|}{$\mathrm{P}=0.243$} & \multicolumn{2}{|c|}{$\mathrm{P}=0.150$} & & & & & $\mathrm{P}=0.31$ & & $\mathrm{P}=0.195$ & \\
\hline \multicolumn{14}{|l|}{ Job: } \\
\hline Job & 100 & 18.130 & 2.537 & 15.870 & 2.06 & 16.62 & 3.73 & 10.790 & 4.39 & 16.520 & 5.15 & 67.140 & 7.000 \\
\hline \multirow[t]{2}{*}{ Non job } & 64 & 18.328 & 2.501 & 15.265 & 2.52 & 16.765 & 3.82 & 11.109 & 4.37 & 16.343 & 5.29 & 66.703 & 8.103 \\
\hline & & \multicolumn{2}{|c|}{$\mathrm{P}=0.771$} & \multicolumn{2}{|c|}{$\mathrm{P}=0.076$} & \multicolumn{2}{|c|}{$\mathrm{P}=0.557$} & $\mathrm{P}=0.80$ & & $P=0.69$ & & $\mathrm{P}=0.167$ & \\
\hline Education & & & & & & & & & & & & & \\
\hline Literacy & 13 & 17.615 & 2.66 & 15.076 & 2.361 & 17.846 & 2.79 & 10.076 & 4.82 & 15.538 & 4.15 & 66.076 & 5.23 \\
\hline School & 105 & 18.066 & 2.61 & 16.846 & 2.279 & 16.838 & 3.70 & 12.114 & 4.62 & 17.123 & 5.05 & 68.190 & 7.39 \\
\hline University & 48 & 18.666 & 2.51 & 14.520 & 1.798 & 16.229 & 4.14 & 10.958 & 3.78 & 14.870 & 5.64 & 64.291 & 7.34 \\
\hline & & $\mathrm{P}=0.10$ & & $\mathrm{P}=0.00$ & & $\mathrm{P}=0.16$ & & $\mathrm{P}=0.02$ & & $\mathrm{P}=0.01$ & & $\mathrm{P}=0.035$ & \\
\hline Family hist & & & & & & & & & & & & & \\
\hline Yes & 34 & 19.235 & 2.06 & 15.235 & 1.84 & 17.529 & 3.87 & 9.000 & 3.67 & 14.558 & 6.56 & 75.558 & 6.11 \\
\hline No & 132 & 17.939 & 2.54 & 15.697 & 2.36 & 16.537 & 3.74 & 11.500 & 4.43 & 16.816 & 4.77 & 78.484 & 8.49 \\
\hline & & $\mathrm{P}=0.05$ & & $\mathrm{P}=0.05$ & & $P=0.69$ & & $\mathrm{P}=0.01$ & & $\mathrm{P}=0.00$ & & $\mathrm{P}=0.075$ & \\
\hline Stage of ca & & & & & & & & & & & & & \\
\hline I & 26 & 18.230 & 2.06 & 15.692 & 2.47 & 18.230 & 2.88 & 11.807 & 4.46 & 16.230 & 5.55 & 80.461 & 7.15 \\
\hline II & 94 & 18.202 & 2.58 & 25.872 & 2.23 & 16.861 & 2.84 & 10.478 & 4.37 & 16.372 & 5.17 & 77.78 & 7.92 \\
\hline & & $\mathrm{P}=0.10$ & & $\mathrm{P}=0.66$ & & $\mathrm{P}=0.03$ & & $\mathrm{P}=0.46$ & & $\mathrm{P}=0.52$ & & $\mathrm{P}=0.819$ & \\
\hline Size of tum & & & & & & & & & & & & & \\
\hline$<2$ & 159 & 18.201 & 2.50 & 15.622 & 2.29 & 16.855 & 3.78 & 11.081 & 4.44 & 16.528 & 5.149 & 78.289 & 8.009 \\
\hline$\geq 2$ & 4 & 19.250 & 3.20 & 16.500 & 1.00 & 15.700 & 2.62 & 8.500 & 3.00 & 10.000 & 7.07 & 70.000 & 6.92 \\
\hline & & $\mathrm{P}=0.33$ & & $\mathrm{P}=0.06$ & & $\mathrm{P}=0.21$ & & $\mathrm{P}=0.19$ & & $\mathrm{P}=0.61$ & & $\mathrm{P}=0.612$ & \\
\hline Radiothera & & & & & & & & & & & & & \\
\hline Yes & 49 & 17.976 & 2.45 & 15.265 & 2.08 & 16.244 & 4.21 & 10.530 & 3.09 & 16.693 & 4.76 & 76.714 & \\
\hline No & 117 & 18.299 & 2.51 & 15.743 & 2.33 & 16.948 & 3.58 & 11.179 & 4.83 & 16.205 & 5.44 & 78.376 & \\
\hline & & $\mathrm{P}=0.52$ & & $\mathrm{P}=0.29$ & & $\mathrm{P}=0.10$ & & $\mathrm{P}=0.00$ & & $\mathrm{P}=0.10$ & & $\mathrm{P}=0.509$ & \\
\hline Chemother & & & & & & & & & & & & & \\
\hline Yes & 149 & 18.441 & 2.45 & 15.516 & 2.23 & 16.879 & 3.85 & 10.677 & 4.382 & 16.140 & 5.42 & 77.657 & 8.255 \\
\hline No & 17 & 16.117 & 1.93 & 16.352 & 2.49 & 15.529 & 2.85 & 13.705 & 3.601 & 18.176 & 2.33 & 79.882 & 6.872 \\
\hline & & $\mathrm{P}=0.06$ & & $\mathrm{P}=0.47$ & & $\mathrm{P}=0.00$ & & $\mathrm{P}=0.19$ & & $\mathrm{P}=0.00$ & & $P=0.606$ & \\
\hline Tamoxifen & & & & & & & & & & & & & \\
\hline Yes & 60 & 18.433 & 2.44 & 16.116 & 2.21 & 17.716 & 3.44 & 10.783 & 5.39 & 16.333 & 5.14 & 79.383 & 6.859 \\
\hline No & 106 & 18.075 & 2.53 & 15.311 & 2.60 & 16.188 & 3.86 & 11.103 & 3.73 & 16.358 & 5.32 & 77.037 & 8.690 \\
\hline & & $\mathrm{P}=0.94$ & & $\mathrm{P}=0.65$ & & $\mathrm{P}=0.10$ & & $\mathrm{P}=0.00$ & & $\mathrm{P}=0.49$ & & $\mathrm{P}=0.002$ & \\
\hline
\end{tabular}

Table 3: Prediction Model for Total QoL.

\begin{tabular}{|c|c|c|c|c|c|c|c|}
\hline Dependent variable & Sum of Squares & df & Mean square & $\mathbf{F}$ & $\mathbf{R}^{2}$ & ${\text { Adjust } \mathbf{R}^{2}}^{2}$ & Sig. \\
\hline Age (Year) & 11.838 & 1 & 0.268 & 3.643 & 0.224 & 0.062 & 0.058 \\
\hline Job & $13.921^{\mathrm{a}}$ & 28 & 0.497 & 1.752 & 0.268 & 0.115 & 0.019 \\
\hline Educational status & 1.639 & 1 & 1.639 & 0.504 & 0.313 & 0.158 & 0.479 \\
\hline Family History of cancer & 3.757 & 28 & 0.134 & 0.777 & 0.140 & -0.040 & 0.779 \\
\hline Stage & 24.882 & 28 & .889 & 2.812 & 0.370 & 0.238 & 0.000 \\
\hline Size of tumor & 0.985 & 28 & 0.035 & 1.616 & 0.252 & 0.096 & 0.038 \\
\hline Type of surgery & 0.420 & 28 & 0.015 & 1.292 & 0.213 & 0.048 & 0.169 \\
\hline Radiotherapy & 6.780 & 28 & .242 & 1.180 & 0.198 & .030 & 0.262 \\
\hline Chemotherapy & 2.374 & 28 & 0.085 & 0.884 & 0.156 & -0.020 & 0.636 \\
\hline Tamoxifen & 11.001 & 28 & 0.393 & 1.956 & 0.290 & 0.142 & 0.006 \\
\hline
\end{tabular}




\section{DISCUSSION}

The QoL refers to "global well-being," that is manifested in elements such as physical, emotional, mental, social, and behavioural components. Well-established QoL tools that measure up health issues have recently become handy (Rizzo et al., 2008; RA Al-Naggar et al., 2013; RA Al-Naggar et al., 2015). Now a days QoL is being used effectively to compare among cancer types, especially in advanced phases (Bottomley et al., 2005). The QoL is now considered an important outcome in cancer clinical trials. It has been shown that assessing the QoL in cancer patients could contribute to improving treatment and could even be as prognostic as medical factors (Montazeri et al., 1996; Goodwin et al., 2004). Above all, studies regarding QoL can aid in the development of more efficient cancer treatment. Monitoring patients by physicians is necessary where QoL hands itself easily in this regard to show up illness progress (Velikova et al., 2008).QoL shows both disease impact and treatment as patients conceive it to be (Spilker, 1996). QoL is affected by factors such as functional stress, perceptions, impairments as well as social opportunities (Testa and Simonson, 1996).

Breast cancer has received the greatest attention among studies interested in cancer patients' QoL for several reasons. First, the number of women with breast cancer is increasing (Stewart et al., 2003, Moro-Valdezate et al., 2013). Second, in terms of early detection and treatment, breast cancer has greatly improved. Survivors now live longer; therefore, studying the QoL in this context is important (Shen et al., 2012; Wyatt et al., 2013). Besides, breast cancer affects women's self-image, and maintenance of QoL is vital in those who have their breasts removed (Exner et al., 2012). In addition, women play an important role as partners, wives, and mothers (Moro-Valdezate et al., 2012; Schleife et al., 2014). Therefore, when a woman develops breast cancer, her family members can also experience the consequences of that illness (Yanez et al., 2011). In fact, breast cancer is a family disease. Other reasons could also be considered, but overall, it is crucial to acknowledge that along with improvements in treatment, the study of QoL in patients with all types of cancer, regardless of gender, is highly relevant.

In the present study, participants were 30 to 67 years old (mean $=49.6 \pm 8.2)$ and the majority of them were 40 years of age or older $(71.7 \%)$. Previous study showed that the average age of these women were $47.7 \pm 10.3$ years and the youngest woman was just 23 years old which is conform with the results about the median age of women diagnosed with breast cancer in China is 48 years, nearly 10 years younger than among women in Western countries (Hu, 2008).

No demographic variables contributed significantly to these women's QoL. This is consistent with a study by Huang et al. (2008) which found no significant relationships between age, marital status, occupation, family income and QoL. There is a significant difference between the quality of life among cancer patients and job.It was noted that employment status was the most important factors that determined QoL (Y1ldiz, 2014).

An earlier study suggested that patients who are longterm cancer survivors or have co-morbid conditions need meticulous consideration (Lee et al., 2015).Among cancer patients, the association between quality of life and cancer stage has proved to be significant. Such a finding goes along with the findings of two earlier studies of the same researcher: one in Malaysia (Al-Naggar et al., 2008), and the other in Yemen (AlNaggar et al., 2011). Other studies also supported our findings (Isikhan et al.2001; Uzun et al.2004). A further supporting finding was stated by Pandey et al., 2006) in which breast specific scales and functional well-being were shown to be influenced by histological grade. Moreover, a significant association is highlighted between quality of life and tumour size among breast cancer patients (Al-Naggar et al., 2008).

With regard to breast cancer patients, radiation therapy after breast-conserving surgery is the standard of care for the majority, because radiation significantly reduces breast cancer recurrence (Early Breast Cancer Trialists' Collaborative Group, 2011). Nevertheless, many women will forego radiation from "fearing the unknown," "getting burnt," "damaging internal parts," and "anticipating tiredness" (Halkett et al., 2008).Fear of radiation may impact QoL both during and after, may decrease compliance with treatment and, ultimately, may add up the chances of having cancer recurrence (Early Breast Cancer Trial ists' Collaborative Group, 2011; Badakhshi et al., 2013).The study found that there was a significant difference between the quality of cancer patients and radiotherapy. This is in agreement with a study with a 15-year follow-up period which demonstrated that women treated with surgery and radiation had very high QoL (Freedman et al., 2010).

\section{ACKNOWLEDGEMENT}

The authors would like to express appreciation to the patients who were willing to participate in this study and their highly cooperation to answer study's questionnaire. Appreciations go also to all staff of Breast centre in Baghdad Hospital, and Hospital of Nuclear Medicine and Radiotherapy, Baghdad, Iraq,

\section{Financial support and sponsorship: Nil.}

Conflict of Interests: There are no conflicts of interest.

\section{REFERENCES}

Abu-Naser D. Arab women who have breast cancer face taboo. The associated Press, 2007. Available at http://www.nbcnews.com/id/ $21455455 / \mathrm{ns} /$ health-cancer/t/breast-cancer-often-untreated-middle-east/.

Al-Hashimi MM, Wang XJ. Breast cancer in Iraq, Incidence trends from 2000-2009.Asian Pac J Cancer Prev, 2014; 15: 281 6.

Al-Naggar RA, Chen R, Ismail F. Quality of life among women with breast cancer from university kebangsaan Malaysia medical centre, Malaysia.J Community Health, 2008; 14: 2.

Al-Naggar RA, MT Osman, YV Bobryshev, SYA Kadir. Ovarian cancer: knowledge of risk factors and symptoms among working 
Malaysian women. Middle-East Journal of Scientific Research, 2013; 14 (4): 549-553.

Al-Naggar RA, W Al-Kubaisy, BW Yap, YV Bobryshev, MT Osman. Attitudes towards colorectalcancer (CRC) and CRC screening tests among elderly Malay patients. Asian Pacific Journal of Cancer Prevention, 2015; 16 (2): 667-674.

Al-Naggar RA, YV Bobryshev, MT Osman. Knowledge of colorectal cancer and associated factorsamong the general population in Malaysia. World Journal of Medical Sciences, 2013; 8 (2): 135-143.

Badakhshi H, Gruen A, Sehouli J, Budach V, BoehmerD. The impact of patient compliance with adjuvant radiotherapy: A comprehensive cohort study. Cancer Med, 2013;2: 712-7.

Bottomley A, Flechtner H, Efficace F, Vanvoorden V, Coens C, Therasse P. Health related quality of life outcomes in cancer clinical trials. Eur J Cancer, 2005;41: 1697-709.

Centers for Disease Control and Prevention \& Lance Armstrong Foundation.A National Action Plan for Cancer Survivorship.Advancing Public Health Strategies. CDC \& Lance Armstrong Foundation, Georgia, 2004 , p. 88

Early Breast Cancer Trialists' Collaborative Group (EBCTCG), Darby S, McGale P, Correa C, Taylor C, Arriagada R, Clarke M, Cutter D, Davies C, Ewertz M, Godwin J, Gray R, Pierce L, Whelan T, Wang Y, Peto R. Effect of radiotherapy after breast-conserving surgery on 10-year recurrence and 15-year breast cancer death: Meta-analysis of individual patient data for 10,801 women in 17 randomised trials. Lancet, 2011; 378: 1707-16.

Early Breast Cancer Trialists' Collaborative Group. Tamoxifen for early breast cancer: an overview of the randomised trials. Lancet,1998; 351: 1451-67.

Exner R, Krois W, Mittlböck M, Dubsky P, Jakesz R, Gnant M, Fitzal F. Objectively measured breast symmetry has no influence on quality of life in breast cancer patients. Eur J SurgOncol,2012; 38: 130-6.

Fisher B, Costantino J, Redmond C, Poisson R, Bowman D, Couture J, Dimitrov NV, Wolmark N, Wickerham DL, Fisher ER. A randomized clinical trial evaluating tamoxifen in the treatment of patients with node-negative breast cancer who have estrogen-receptor-positive tumors.NEngl J Med, 1989; 320: 479-84.

Fisher B, Costantino JP, Redmond CK, Fisher ER, Wickerham DL, Cronin WM. Endometrial cancer in tamoxifen-treated breast cancer patients: findings from the National Surgical Adjuvant Breast and Bowel Project (NSABP) B-14. J Natl Cancer Inst, 1994; 86: 527-37.

Fisher B, Costantino JP, Wickerham DL, Redmond CK, Kavanah M, Cronin WM, Vogel V, Robidoux A, Dimitrov N, Atkins J.Tamoxifen for prevention of breast cancer: report of the National Surgical Adjuvant Breast and Bowel Project P-1 Study. J Natl Cancer Inst, 1998; 90: 1371-88.

Freedman GM, Li T, Anderson PR, Nicolaou N, Konski A. Health states of women after conservative surgery and radiotherapy for breast cancer.Breast Cancer Res Treat, 2010; 121: 519-26.

Global Health Observatory (GHO), 2012.Cancer mortality and morbidity.Available at www.who.org. (Retrieved on 3rdApril, 2016).

Globocan, 2008. Breast cancer incidence and mortality worldwide, 2008.International Agency for Research on Cancer.

Goodwin PJ, Ennis M, Bordeleau LJ, Pritchard KI, Trudeau ME, Koo J, Hood N. Health-related quality of life and psychosocial status in breast cancer prognosis: analysis of multiple variables. J ClinOncol, 2004; 22: 4184-92.

Gottardis MM, Robinson SP, Satyaswaroop PG, Jordan VC.Contrasting actions of tamoxifen on endometrial and breast tumor growth in the athymicmouse.Cancer Res, 1988; 48:812-5.

Halkett GK, Kristjanson LJ, Lobb EA. 'If we get too close to your bones they'll go brittle': Women's initial fears about radiotherapy for early breast cancer.Psychooncology,2008; 17: 877-84.

Hu DR, 2008. Breast cancer epidemiology research results: Chinese women is nearly 10 years younger than women in Western countries when they were diagnosed with breast cancer http://health.people.com.cn/GB/14272439.html.
Huang Z.Z., C.X. Wu, Y. Zheng.Prevalence of depression and quality of life among female breast cancer survivors in Shanghai. China Oncol, 2008; 18: 204-8.

Ibrahim G. Alghamdi, Issam I. Hussain, Mohamed S. Alghamdi, Mohamed A. El-Sheemy. The incidence rate of female breast cancer in Saudi Arabia: an observational descriptive epidemiological analysis of data from Saudi cancer registry 2001-2008. Breast Cancer Target Ther, 2013; 5:103-9.

International Agency for Research on Cancer GLOBOCAN, 2012. Estimated Cancer Incidence, Mortality and Prevalence Worldwide in 2012. International Agency for Research on Cancer, World Health Organization: Lyon, France, 2012. http://globocan.iarc.fr/Pages/fact_ sheets_cancer.aspx. Retrieved 26 January 2014.Section on Cancer Information.

Iraqi National Cancer Research Center. 2015. Brief historical introduction, establishing the breast \& cervical cancer research unit and the Iraqi National Cancer Research Center/Program.

Isikhan V, Guner P, Komurcu S, Ozet A, Arpaci F, Ozturk B. The relationship between disease features and quality of life in patients with cancer. Cancer Nurs, 2001; 24: 490-5.

Lee SY, Kim SJ, Shin J, Han KT, Park EC. The impact of job status on quality of life: general population versus long-term cancer survivors. Psychooncology, 2015; 24: 1552-9.

McCabe MS, Bhatia S, Oeffinger KC, Reaman GH, Tyne C. American Society of Clinical Oncology Statement: Achieving HighQuality Cancer Survivorship Care. J ClinOncol,2013; 31: 631-40.

Montazeri A, Gillis CR, McEwen J. Measuring quality of life in oncology: is it worthwhile? Part I. Meaning, purposes, and controversies. Eur J Cancer Care, 1996; 5:159-67.

Moro-Valdezate D, Peiró S, Buch-Villa E, Caballero-Gárate A, Morales-Monsalve MD, Martínez-Agulló A, Checa-Ayet F, OrtegaSerrano J. Evolution of HealthRelated Quality of Life in Breast Cancer Patients during the First Year of Follow Up. .J Breast Cancer, 2013; 16: 104-11.

Moro-Valdezate D, Peiró S, Buch-Villa E, Caballero-Gárate A, MoralesMonsalve MD, Martínez-Agulló A, Checa-Ayet F, Ortega-Serrano J. Factors associated with health-related quality of life in a cohort of Spanish breast cancer patients. Breast Cancer,2012; 21: 442-52.

Najla A. Lakkis, Salim M. Adib, Mona H. Osman. Breast cancer in Lebanon: Incidence and comparison to regional and western countries Cancer Epidemiol, 2010; 34: 221-5.

National Cancer Institute. Cancer Treatment and Survivorship. Facts and Figures 2012-2013. American Cancer Society, USA, 2012, p. 1 44.

Ozmen V, Ozcinar B, Karanlik H, Cabioglu N, Tukenmez M, Disci R, Ozmen T, Igci A, Muslumanoglu M, Kecer M, Soran A. Breast cancer risk factors in Turkish women-a University Hospital based nested case control study. World J SurgOncol, 2009;7: 37.

Pandey M, Thomas BC, Ramdas K, Ratheesan K. Early effect of surgery on quality of life in women with operable breast cancer.Jpn $\mathrm{J}$ ClinOncol,2006; 36: 468-72.

Parkin DM. Global cancer statistics 2002, CA: A Cancer Journal for Clinicians, 2005; 55:74-108

Rauscher, G, AL-Alem U, Richard BW. Does psychosocial stress play a role in the etiology of aggressive breast cancer? A crosssectional study.CancerEpidemiol Biomarkers Prev,2011; 20: A91.

Rizzo PB, Maronato F, Marchiori C, Gaya A. Long-term quality of life after total laryngectomy and postoperative radiotherapy versus concurrent chemoradiotherapy for laryngeal preservation.Laryngoscope, 2008; 118: 300-6.

Salim EI, Moore MA, Al-Lawati JA, Al-Sayyad J, Bazawir A, Bener A, Corbex M, El-Saghir N, Habib OS, Maziak W, Mokhtar HC, Seif-Eldrin IA, Sobue T. Cancer epidemiology and control in the arab world - past, present and future. Asian Pac J Cancer Prev, 2009; 10: 3-16.

Schleife H, Sachtleben C, FinckBarboza C, Singer S, Hinz A. Anxiety, depression, and quality of life in German ambulatory breast cancer patients. Breast Cancer,2014; 21: 208-13. 
Shen FR, Liu M, Zhang X, Feng YH, Zhou LS, Chen YG. Health-related quality of life among breast cancer patients and its influencing factor in a Chinese population.Asian Pac J Cancer Prev, 2012; 13:3747-50.

Spilker B. Quality of Life and Pharmacoeconomics in Clinical Trials. Philadelphia: Lippincott-Raven.

Stewart BW, Paul Kleihues P, 2003. World Cancer Report Lyon, France, International Agency Research on Cancer 2003.

Testa MA, Simonson DC (1996).Assessment of quality of life outcomes.NewEng J Med,334: 835-40.

Uzun Ö, Aslan FE, Selimen D, Koc M. Quality of life in women with breast cancer in Turkey.J Nursing Scholar, 2004; 36: 207-13.

Vasconcelos AL, Nunes B, Duarte C, Mendonça V, Ribeiro J, Jorge M, MonteiroGrillo I.Tamoxifen in breast cancer ipse dixit in uterine malignant mixed Mulleriantumor and sarcoma-A report of 8 cases and review of the literature.RepPractOncolRadiother, 2013; 18: 251-60.

Velikova G, Awad N, Coles-Gale R, Wright EP, Brown JM, Selby $\mathrm{P}$. The clinical value of quality of life assessment in oncology practice: a qualitative study of patient and physician views. Psychooncology, 2008; 17: 690-8.

World Cancer Report 2014, 2014. Edited by Bernard Stewart and Christopher P. Wild. IARC Nonserial Publication.
Wyatt G, Sikorskii A, Tamkus D, You M. Quality of life among advanced breast cancer patients with and without distant metastasis.Eur J Cancer Care (Engl), 2013; 22: 272-80.

Yanez B, Thompson EH, Stanton AL, 2011. Quality of life among Latina breast cancer patients: a systematic review of the literature. J Cancer Surviv, 2011; 5: 191-207.

Yildiz. Assessment of the quality of life in Turkish breast cancer patients. J Breast Health, 2014; 10: 216-21.

\section{How to cite this article:}

Al-Naggar RA, Osman MT, Nameer Al-Baghdadi. Study of quality of life and characteristic factors in women with breast cancer undergoing different types of therapy. J App Pharm Sci, 2016; 6 (09): 147-152. 